\title{
Encouraging a bare minimum while striving for the gold standard: a response to the updated WHO-WFSA guidelines
}

\author{
Simon Hendel, MBBS (Hons), FANZCA, GDip Journalism (1) P Paulin Banguti, MD • \\ Rediet S. Workneh, MD • Emilia Pinto, MD - Tom Coonan, MD, \\ FRCPC $\cdot$ Robert Neighbour, MSc $\cdot$ Haydn Perndt, MBBS, FANZCA $\cdot$ Alison Froese, MD, \\ FRCPC $\cdot$ Kelly McQueen, MD, MPH, FASA
}

Received: 28 June 2018/Revised: 12 July 2018/Accepted: 12 July 2018/Published online: 29 August 2018

(C) Canadian Anesthesiologists' Society 2018

\section{To the Editor,}

We read with interest the recently published World Health Organization-World Federation of Societies of Anesthesia (WHO-WFSA) International Standards for the Practice of Safe Anesthesia. ${ }^{1,2}$ We thank Dr. Gelb and his colleagues for their effort to provide ideal global safety guidelines for providers in every setting. These aspirational guidelines are undoubtedly the gold standard, but we argue that they are unrealistic for many providers.

These standards have been updated in an era of global surgery. Despite perpetual neglect, surgery is now scaling up in low and middle-income countries (LMICs). The World Bank and the WHO have committed to providing 28 of 44 basic surgeries in every first referral hospital ${ }^{3}$ and are

This letter is accompanied by a reply. Please see Can J Anesth 2018 65: this issue.

This letter is jointly published in the Canadian Journal of Anesthesia and Anesthesia \& Analgesia.

S. Hendel, MBBS (Hons), FANZCA, GDip Journalism ( $\square$ ) Department of Anaesthesia and Perioperative Medicine, The Alfred Hospital and Monash University, Melbourne, Australia e-mail: s.hendel@alfred.org.au; simon.hendel@monash.edu

P. Banguti, MD

King Faisal Hospital and Program Director, College of Medicine and Health Sciences, University of Rwanda, Kigali, Rwanda

R. S. Workneh, MD

Addis Ababa University, Addis Ababa, Ethiopia

E. Pinto, MD

Maputo Pain Clinic, Maputo, Mozambique

T. Coonan, MD, FRCPC

Dalhousie University, Halifax, NS, Canada working with individual countries' Ministries of Health to achieve this. National plans for surgery, obstetrics, and anesthesia ${ }^{4}$ are underway, and while "anesthesia" is peripherally included in planning discussions, anesthesia societies and providers are not significantly engaged in these efforts. In many LMICs, anesthesia providers are often not on equal professional footing with surgeons. Consequently, they are not equally or fairly compensated, and their voice is not always heard.

Nevertheless, if these aspirational standards are to be globally achieved, the voices of anesthesia providers in LMICs must be heard. While we appreciate the necessity of such topdown standards to encourage health care systems to invest in essential anesthesia safety equipment and medicines, we are compelled to ask: How will we, the international community, support anesthesia providers in LMICs in the meantime? We must acknowledge that patient safety can be achieved in the absence of the ideal-despite forever striving for it.

We do a disservice to those who rely on a bare minimum by implying that they should have oxygen, safety monitors,

R. Neighbour, MSc

Diamedica, Bratton Fleming, UK

H. Perndt, MBBS, FANZCA

Department of Anaesthesia, Royal Hobart Hospital, Hobart, Tasmania, Australia

A. Froese, MD, FRCPC

Departments of Anesthesiology, Pediatrics and Physiology, Queen's University, Kingston, ON, Canada

K. McQueen, MD, MPH, FASA

Departments of Anesthesiology and Surgery Division of Ambulatory Surgery, Vanderbilt Anesthesia Global Health \& Development, Vanderbilt Institute for Global Health, Vanderbilt University School of Medicine and Vanderbilt University Medical Center, Nashville, TN, USA 
and essential medicines at all times. By "highly recommending" items such as carbon dioxide monitoring that remain a luxury in many environments, there is the risk that essential surgery will not be done in lieu of the idealor that the guidelines will be dismissed as a whole because parts are too idealistic. This is not the pragmatism that patients need-but it is exactly the risk that bare minimum guidelines mitigate.

Aspirational guidelines - such as those implied by the WHO-WFSA document-are essential, but on the other hand practical and evidence-based stepping stones must also be offered to support those who cannot yet reach this ideal. Patient safety is not all or nothing. It is a continuum where a rising tide will eventually lift all ships.

In this spirit, we ask the global anesthesia community to embrace a bare minimum for safe practice as an important addendum to these essential, but not yet universally achievable guidelines. ${ }^{5}$ Bare minimum guidelines represent a metaphorical line in the sand, beyond which surgery should not occur, but by the same token, every anesthesia provider must have the chance to provide safe anesthesia today while working towards the ideal tomorrow. Without practical solutions found in the real world, we risk being irrelevant partners to our peers who live and work in it.

Conflicts of interest None declared.
Editorial responsibility This submission was handled by Dr. Hilary P. Grocott, Editor-in-Chief, Canadian Journal of Anesthesia.

\section{References}

1. Gelb AW, Morriss WW, Johnson W, Merry AF, International Standards for a Safe Practice of Anesthesia Workgroup. World Health Organization-World Federation of Societies of Anaesthesiologists (WHO-WFSA) International Standards for a Safe Practice of Anesthesia. Can. J Anesth 2018; 65: 698-708.

2. Gelb AW, Morriss WWS, Johnson W, et al.; International Standards for a Safe Practice of Anesthesia Workgroup. World Health Organization - World Federation of Societies of Anaesthesiologists (WHO-WFSA) International Standards for a Safe Practice of Anesthesia. Anesth Analg 2018; 126: 2047-55.

3. Mock CN, Donkor P, Gawande A, Jamison DT, Kruk ME, Debas $H T$. Essential Surgery: key messages of this volume. In: Debas HT, Donkor P, Gawande A, Jamison DT, Kruk ME, Mock CN (Eds). Essential Surgery: Disease Control Priorities, Third Edition (Volume 1) Washington (DC); 2015.

4. World Health Organization. Surgical Care Sytems Strengthening. Developing National Surgical, Obstetric and Anaesthesia Plans. Available from URL: http://www.who.int/surgery/publications/ scss/en/ (accessed July 2018).

5. McQueen K, Coonan T, Ottaway A, et al. The bare minimum: the reality of global anaesthesia and patient safety. World J Surg 2015; 39: 2153-60. 